\title{
Treatment of subfoveal choroidal neovascularisation in age related macular degeneration: focus on clinical application of verteporfin photodynamic therapy
}

\author{
Gisèle Soubrane, Neil M Bressler
}

Age related macular degeneration (AMD) is a degenerative disease usually occurring in people over the age of 50 years. Macular involvement can cause vision impairment and result in legal blindness due to atrophic or neovascular complications. ${ }^{1}$

The definition of specific lesions associated with AMD has led to classifications of the condition and its severity. ${ }^{1}$ The "dry" or non-neovascular form of AMD is characterised by drusen or abnormalities of the retinal pigment epithelium (RPE) such as atrophy, or hypopigmentation or hyperpigmentation. "Wet" or neovascular AMD is manifested by choroidal neovascularisation $(\mathrm{CNV}) .^{2}$ The prevalence of non-neovascular AMD is greater than that of neovascular AMD. However, $10-20 \%$ of patients with non-neovascular AMD progress to neovascular AMD. ${ }^{34}$ Severe vision loss usually occurs when CNV extends under the centre of the foveal avascular zone (subfoveal CNV). ${ }^{5}$ Neovascular proliferation from the choriocapillaris extends through Bruch's membrane, invades the space under the RPE and leaks serous fluid, including lipid or blood, into this space. ${ }^{6}$ This neovascular process is associated with the development of fibrous tissue which replaces the normal architecture of the outer retina, often leading to severe, irreversible loss of central vision. ${ }^{7}$ Neovascular AMD, although present in less than $20 \%$ of all patients with AMD, is responsible for approximately $90 \%$ of cases with severe vision loss. ${ }^{8}$ It occurs in up to 200000 individuals in the USA each year, ${ }^{9}$ with approximately 500000 new cases throughout the world. Without treatment, most affected eyes have poor central vision $(\leqslant 20 / 200)$ within 2 years. ${ }^{10}$

The prevalence of AMD has been estimated in several epidemiological studies and ranges from $2 \%$ to over $10 \%$, depending on the working definition of $\mathrm{AMD}$, the grading system used, and the age and environment of the study population. ${ }^{3}$ All the studies, however, point to the association between AMD prevalence and age. AMD occurs most frequently in people above 50 years of age, with a strong increase in prevalence in people over 65 years of age.$^{11-15}$ This rapid increase in AMD prevalence with age will probably pose a growing health problem for developed countries because of the increasing proportion of the population in older age groups. By 2020, as many as 7.5 million people over 65 years of age may suffer from vision loss due to AMD. ${ }^{16}$ Data from the UK have shown that the number of new registrations of blindness due to AMD has increased by $30-40 \%$ in the past 50 years. ${ }^{17}$

Untreated CNV secondary to AMD is usually associated with a poor vision outcome. ${ }^{10}$ The risk of severe visual acuity loss in untreated cases, for which photocoagulation would have been beneficial, can be at least twice that of cases treated with laser photocoagulation. ${ }^{5}$ However, photocoagulation is indicated in only a small proportion of cases. ${ }^{18-21}$ Until now, no effective treatment was available for most patients presenting with neovascular AMD. ${ }^{22}{ }^{23}$

Patients with CNV secondary to AMD in one eye are at high risk of severe vision loss in the fellow eye, which, when it occurs, will result in a significant adverse impact on the patient's quality of life. About $50 \%$ of patients presenting with bilateral CNV are legally blind within 5 years, compared with $12 \%$ of patients with unilateral CNV. In the latter group, however, CNV can develop in the fellow eye. ${ }^{24}$ Recent studies have also indicated that the prognosis of the fellow eye is strongly affected by four risk factors: three characteristics of the macula (presence of five or more drusen, focal hyperpigmentation, and one or more large drusen) and systemic hypertension. ${ }^{24}$ The 5 year incidence of CNV in the fellow eye has been estimated to be $87 \%$ in patients with all four factors, compared with $7 \%$ in patients with none of these risk factors. ${ }^{24}$ Thus, the four CNV risk factors are important for the identification of patients who are at risk of developing $\mathrm{CNV}$ in the fellow eye.

The ideal treatment for neovascular AMD should stabilise visual acuity or prevent the development of severe visual acuity loss, as well as preserve or limit the destruction of the retina overlying the choroidal neovascular lesion while destroying the pathological choroidal neovasculature. Such treatment would benefit most patients with CNV, without causing side effects, and would improve the patient's quality of life. Given the public health impact of neovascular AMD, many therapies are under investigation for this condition, leading to an explosion of information in this field. This paper reviews current and experimental treatments for neovascular AMD, focusing on the impact of verteporfin therapy (Visudyne; Novartis Ophtalmia, Bülach, Switzerland).

\section{Treatments with proved benefits}

LASER PHOTOCOAGULATION

Laser photocoagulation based on fluorescein angiography was the only treatment of proved efficacy for neovascular AMD in large scale, randomised clinical trials throughout the $1990 \mathrm{ss}^{25}$ The aim of laser photocoagulation is to treat the entire neovascular lesion in order to limit any subsequent destructive effects of CNV and therefore halt or slow the loss of visual acuity. Four important determinants in the use of laser photocoagulation are: visual acuity, CNV composition on fluorescein angiography, size of the entire choroidal neovascular lesion, and location of the lesion relative to the centre of the macula on fluorescein angiography. Laser photocoagulation has been shown to be beneficial in the treatment of CNV with well defined (well demarcated) boundaries not extending under the centre of the foveal avascular zone (extrafoveal or juxtafoveal CNV). ${ }^{26-28}$ Further, for CNV that extends under 
the centre of the foveal avascular zone (subfoveal CNV), not only should the lesion be well demarcated and include evidence of classic CNV, but its size should also be $\leqslant 3.5$ MPS (Macular Photocoagulation Study) disc areas for new lesions and $\leqslant 6.0$ MPS disc areas for recurrent lesions. $^{529}$

Photocoagulation of subfoveal CNV, however, usually results in an immediate decrease of central vision, ${ }^{5}$ which may be delayed by perifoveal photocoagulation. ${ }^{30}$ The use of a thermal laser destroys overlying retinal tissue, which can lead to an immediate and irreversible loss of residual visual function. ${ }^{5}$ In addition, the inner choroid may be irreversibly damaged by this technique.

High rates of recurrence of CNV have been noted with laser photocoagulation. About $50 \%$ of laser treated eyes experience persistent or recurrent $\mathrm{CNV}$ within 3 years of treatment. ${ }^{28}$ These recurrences usually lead to further deterioration in visual acuity. ${ }^{28}$ Apart from inadequate coverage of the area to be treated by laser photocoagulation or an inadequate level of energy used, recurrence may also be due to the fact that the underlying disease process continues and stimulates renewed neovascular growth.

It is estimated that only $10-20 \%$ of patients with neovascular AMD would benefit from laser photocoagulation that would reduce the risk of additional severe vision loss compared with no treatment. ${ }^{18}{ }^{31}$ This has led to the development and investigation of new modalities to treat neovascular AMD.

\section{PHOTODYNAMIC THERAPY}

Photodynamic therapy is a new treatment which has recently been proved in large scale, randomised clinical trials to reduce the risk of vision loss in selected cases of AMD with CNV that extend under the centre of the foveal avascular zone. ${ }^{32}$ Photodynamic therapy is a two step technique that can be performed as an outpatient procedure. The first step of the process involves an intravenous infusion of a light activated drug; the second step is activation of the drug by non-thermal light at a wavelength absorbed by the drug in the presence of oxygen. ${ }^{33}$ This probably results in the formation of cytotoxic oxygen species such as singlet oxygen and free radicals, which can damage cellular structures. This process may then lead to platelet activation and subsequent thrombosis and occlusion of new vessels within the treated area as well as destruction of fibrovascular tissue in the immediate vicinity of the new vessels. ${ }^{34}$

Numerous studies have found that light activated drugs can be retained preferentially in tumours ${ }^{35}$ and that photodynamic therapy leads to tumour death via occlusion of the tumour vasculature as well as a direct cytotoxic effect. ${ }^{36}$ These studies suggested that photodynamic therapy could be useful in the treatment of ocular diseases which are characterised by neovascularisation, such as AMD.

Several features of a light activated drug can affect its efficacy. The selectivity of the drug can determine the degree of iatrogenic damage to diseased versus healthy tissue. An ideal selectivity for treating CNV would be a drug that causes damage only to the neovascularisation and not to any surrounding tissue. The absorption spectrum of the drug defines the optimum wavelength of the activating light and the depth of light penetration. A long wavelength of light may be able to penetrate through lens opacity in older people with AMD and penetrate through most of the retinal structures. The photosensitising potency of an agent determines the light dose required for optimum specificity - the greater the potency, the less thermal reaction caused by the light dose required. The pharmacokinetic properties of the drug determine the timing of light administration and the period of risk of indiscriminate damage to the skin and eyes. Light activated drugs previously used in medicines such as haematoporphyrin derivative (HPD) and porfimer sodium (Photofrin, Axcan Pharma Inc) were limited by a weak photosensitising potency and production of prolonged skin photosensitivity lasting up to 12 weeks. ${ }^{33}$ Ideally, to minimise the time taken to treat a patient, these pharmacokinetic properties should allow a brief time between administration of the drug and light application for activation. In addition, the time in which indiscriminate damage to the skin and eyes might occur is decreased if a drug clears rapidly from the body.

The advantages of photodynamic therapy include that it is selective in affecting choroidal neovascular tissue with minimal damage of the photoreceptors overlying the neovascular tissue that are viable at the time of treatment. Therefore, photodynamic therapy may lead to destruction of CNV, thus preventing further damage that would lead to impairment of visual acuity. This technique may even be able to improve visual acuity in some cases, where part of the decreased vision is caused by subretinal fluid or haemorrhage which could clear with destruction of the neovascular tissue. ${ }^{37} 38$

\section{VERTEPORFIN}

Verteporfin (benzoporphyrin derivative monoacid, BPDMA, Visudyne) is a new potent second generation light activated drug for photodynamic therapy, which is derived from porphyrin and consists of two regioisomers. ${ }^{39}$ It is lipophilic and is taken up by plasma membrane cells. ${ }^{40}$ It is under investigation for potential use in the treatment of a variety of conditions including skin cancer, psoriasis, and the neovascular form of AMD. Verteporfin therapy has been shown to cause little damage to physiological intraocular tissues when used at a proper drug dose, dye dose, and timing of photoactivation. ${ }^{41}$

\section{Features of verteporfin}

Verteporfin is injected intravenously as a liposomal preparation to provide solubility and to increase selectivity. Once in the circulation, verteporfin partitions into lipoproteins and complexes with low density lipoprotein (LDL). In vitro studies suggest that cellular uptake of verteporfin-LDL complexes is mediated by LDL receptors. ${ }^{40}$ These receptors are expressed on endothelial cells, and their expression is increased in neovasculature, ${ }^{38} 42$ thus leading to an increase in LDL uptake. ${ }^{43}$ This mechanism may explain, in part, the preferential accumulation of verteporfin in neovascular tissues, which leads to an increased selectivity of the photodynamic therapy effects of verteporfin on CNV and not on other retinal vessels that overlie the $\mathrm{CNV}^{40}{ }^{42-46}$

Following intravenous injection, verteporfin can accumulate rapidly in the choroid, RPE and photoreceptors of the rabbit eye. ${ }^{48}$ Because verteporfin has a long absorption wavelength with a peak at $689 \mathrm{~nm}$, light that activates the drug may be able to penetrate more deeply into outer retinal tissues than the wavelength of light that is required to activate $\mathrm{HPD}{ }^{49}$ Verteporfin is cleared rapidly from the body within the first 24 hours. In addition, it appears to be cleared from the choroid, RPE, and retina faster than HPD, ${ }^{47}$ so these structures are photosensitive for a shorter time. Verteporfin is no longer detected in the outer retina 2 hours after injection, whereas HPD is detectable 48 hours after injection. ${ }^{47}$ Light exposure after 24 hours appears to induce only a minimal skin photosensitivity reaction in mice. ${ }^{50}$ When injected intravenously, verteporfin has a plasma half life of 2-5 hours in different species (QLT Inc, unpublished data, 1996). 


\section{Preclinical studies}

Preclinical studies have shown that verteporfin is effective in treating experimental choroidal melanomas, ${ }^{45}$ in causing vascular occlusion in a rabbit choroid without damage to the neuroretinal or the basement membrane of the RPE, ${ }^{49}$ in producing occlusion of experimental $\mathrm{CNV},{ }^{51}$ and in inducing cessation of leakage from $\mathrm{CNV}$ induced after laser injury to monkeys. ${ }^{5152}$ Repeated treatments with verteporfin in normal monkey eyes demonstrated dose dependent recovery of the capillaries with minimal damage to photoreceptors. ${ }^{53}$ All these findings suggested that verteporfin therapy should be evaluated for the treatment of CNV in humans, and helped to define the range of treatment parameters that could potentially be used in clinical trials.

\section{Phase I/II studies}

A phase I/II investigation was designed to evaluate the safety and maximum tolerated doses of verteporfin therapy for the treatment of patients with CNV. These studies were also designed to determine if fluorescein dye leakage from CNV could be stopped by verteporfin therapy without visual acuity loss, on the assumption that cessation of leakage might stop lesion growth and prevent further vision loss. ${ }^{54-56}$ In a report on single treatments, the results showed that light activated verteporfin could cause short term (1-4 weeks) cessation of fluorescein leakage from CNV without angiographic damage to retinal blood vessels or loss of vision. ${ }^{54}$ The data showed that the maximum tolerated light dose was less than $150 \mathrm{~J} / \mathrm{cm}^{2}$ (above this, loss of selectivity with retinal vascular occlusion occurred). A light dose of $25 \mathrm{~J} / \mathrm{cm}^{2}$ was reported to be the minimum dose at which an effect on fluorescein leakage could be produced. In almost all cases, fluorescein leakage recurred by 12 weeks after the initial treatment, even in patients who had received a maximum tolerated light dose. The investigators believed that it was highly probable that fluorescein leakage 12 weeks after an initial treatment would result in continued growth of the neovascular lesion, accompanied by progressive vision loss. Multiple treatments using verteporfin therapy to stop fluorescein leakage from CNV were therefore evaluated to determine whether this would prevent the progressive growth of the neovascular lesion and any vision loss associated with this growth. ${ }^{55}$ Repeated treatments consistently caused short term cessation of fluorescein leakage from CNV without causing angiographic damage to the retinal blood vessels or short term visual acuity loss. ${ }^{55}$ Nevertheless, return of leakage from CNV was typically noted by 12 weeks after a retreatment (although often involving an area smaller than that noted before treatment), suggesting that periodic treatment for an indeterminate length of time might be required in future evaluations of verteporfin therapy for CNV.

Systemic safety of verteporfin was very good in this phase I/II investigation. Specifically, the most frequent adverse event of this open label study was headache $(4.7 \%)$, while other adverse events occurred in less than $4 \%$ of patients, with no skin photosensitivity reported. ${ }^{54-56}$

The results from the phase I/II studies suggested that a potentially effective dose of verteporfin to be considered for phase III trials would be $6 \mathrm{mg} / \mathrm{m}^{2}$ body surface area, which would be infused intravenously over 10 minutes. ${ }^{54} 55$ Irradiation with a diode laser at $689 \mathrm{~nm}$ was applied 15 minutes after the start of the infusion; the light dose delivered was between 50 and $100 \mathrm{~J} / \mathrm{cm}^{2}$ at an intensity of 600 $\mathrm{mW} / \mathrm{cm}^{2}$ over a period of 83 seconds. This regimen had the greatest number of eyes with absence of fluorescein leakage from classic CNV 12 weeks after initial treatment $(30 \%$; three of 10 patients), and $36 \%$ (four of 11 patients) gained three or more lines of vision with this treatment with short

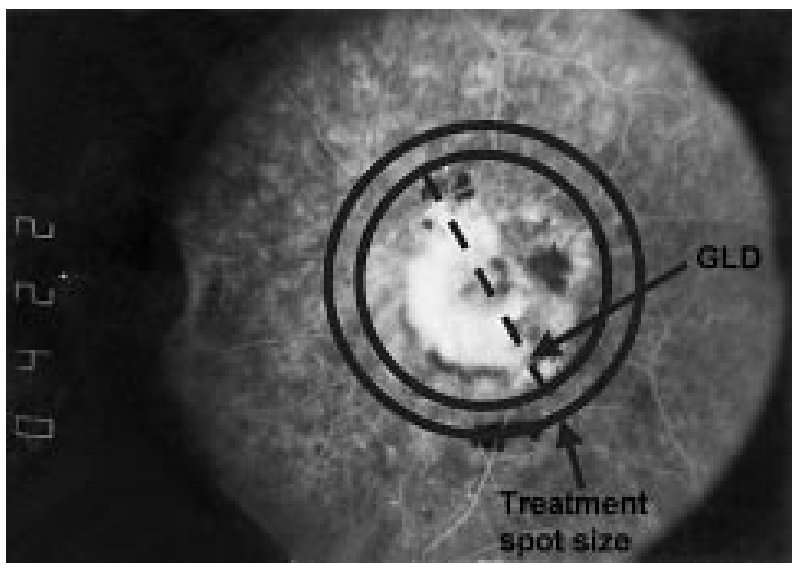

Figure 1 The spot size of the light used to activate verteporfin is calculated by measuring the greatest linear dimension (GLD) of the lesion on the retina from the fluorescein angiogram, adding $1000 \mu \mathrm{m}$ to ensure a sufficient margin to cover the whole lesion. (Reproduced with permission from Treatment of Age-related Macular Degeneration With Photodynamic Therapy (TAP) Study Group. Photodynamic therapy of subfoveal choroidal neovascularisation in age related macular degeneration with verteporfin. Arch Ophthalmol 1999;117:1329-45.)

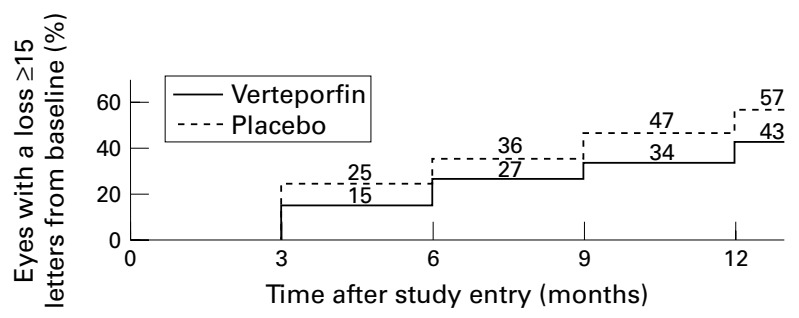

Figure 2 Kaplan-Meier estimates of the cumulative proportion of eyes treated with verteporfin or given placebo with moderate visual acuity loss $(\geqslant 15$ letters or approximately $\geqslant 3$ lines) at each 3 month study visit over time during the first 12 months of the TAP investigation. (Reproduced with permission from Treatment of Age-related Macular Degeneration With Photodynamic Therapy (TAP) Study Group. Photodynamic therapy of subfoveal choroidal neovascularisation in age related macular degeneration with verteporfin. Arch Ophthalmol 1999;117:1329-45.)

term follow up. The $50 \mathrm{~J} / \mathrm{cm}^{2}$ light dose in this regimen was associated with the highest percentage of patients with absence of leakage at 4 weeks $(57 \%)$ and the lowest percentage of patients with progression of classic CNV at 12 weeks. These and other factors led to the selection of this regimen for future trials.

\section{Phase III studies}

Two phase III trials were begun in December 1996, termed the Treatment of Age related macular degeneration with Photodynamic therapy (TAP) investigation in Europe and North America. The objective of the TAP investigation was to determine whether verteporfin therapy, compared with placebo, could reduce the risk of vision loss in eyes with subfoveal CNV secondary to AMD. ${ }^{32}$ A total of 609 participants were randomly assigned $(2: 1)$ to verteporfin or placebo. All patients and treating ophthalmologists were masked to the treatment assignment, as were the visual acuity examiners and photograph graders. The key eligibility criteria for inclusion were a best corrected visual acuity of approximately $20 / 40$ to $20 / 200$, subfoveal CNV secondary to AMD with evidence of classic CNV, and a greatest linear dimension (GLD) of the entire lesion on the retina of $5400 \mu \mathrm{m}$ or less.

The treatment spot size was determined after measuring the GLD of the entire lesion with a millimetre ruler placed on the fluorescein angiogram, in which the angiographic image was magnified 2.5 times. Dividing the GLD by 2.5 resulted in the approximate GLD of the lesion on the retina. An additional $1000 \mu \mathrm{m}$ was added to this dimension 
A

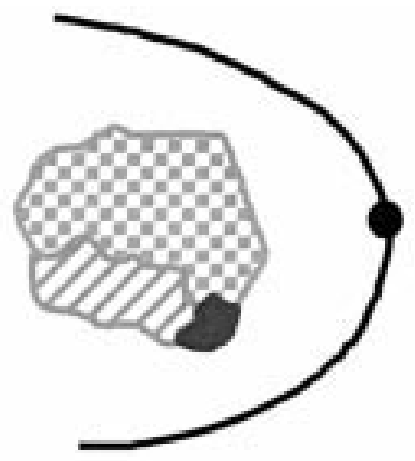

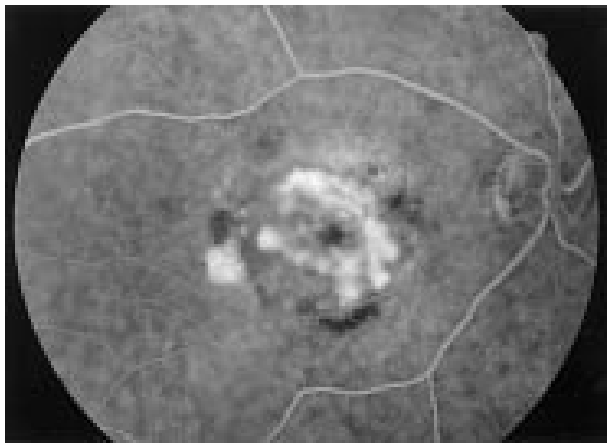

Predominantly classic, classic CNV occupying $\geq 50 \%$ of the entire lesion area.

B
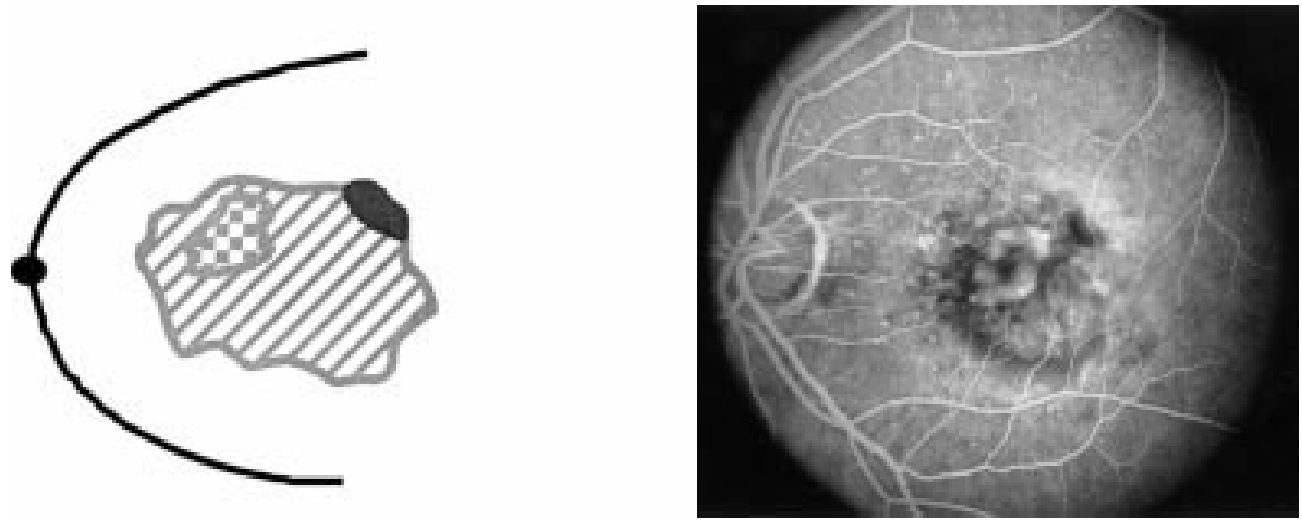

Minimally classic, classic CNV occupying $<50 \%$ but $>0 \%$ of the entire lesion area.

C
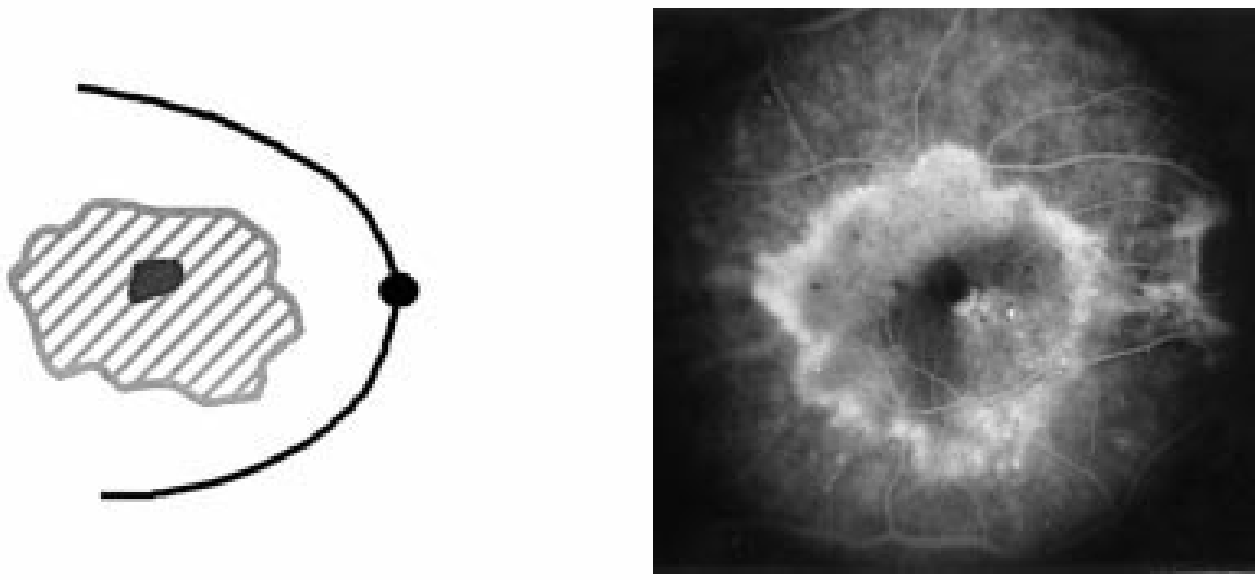

No classic, classic CNV occupying $0 \%$ of the entire lesion area (ie occult only). 
to provide a $500 \mu \mathrm{m}$ margin of additional treatment to ensure that the entire CNV would be treated and to compensate for any slight movements of the study eye during light application (Fig 1). The laser parameters were set up to deliver this spot size onto the retina, taking into account the magnification of the contact lens to be used during light application. Because the dose of verteporfin depended on the patient's body surface area, the height and weight of the patient had to be determined on the day of treatment. A $30 \mathrm{ml}$ solution of either placebo ( $5 \%$ dextrose in water) or verteporfin ( $6 \mathrm{mg} / \mathrm{m}^{2}$ body surface) was prepared and this was infused into the patient over $10 \mathrm{~min}-$ utes; then, 15 minutes after the start of the drug infusion, light was applied for 83 seconds.

Patients were scheduled to return approximately 3 months after each evaluation (within 2 weeks before or after that date). Retreatment could be considered if there was no serious adverse event judged to be associated with any previous photodynamic therapy. Retreatment with placebo or verteporfin (as assigned at the baseline examination) was administered to the patient if the treating ophthalmologist noted any leakage from any CNV (classic or occult) on a fluorescein angiogram taken every 3 months after the initial or subsequent follow up examination for up to 2 years. The treatment parameters were similar to those at baseline, except that the treatment spot size $(\mathrm{GLD}+1000 \mu \mathrm{m})$ had to span all areas of leakage from classic or occult CNV (even if these areas were noncontiguous), as well as any hypofluorescence from blood or a fibrovascular pigment epithelium contiguous to CNV. The lesion to be retreated did not include any scar tissue that stained (but did not leak fluorescein from its boundaries), or hyperfluorescence that was not from visible blood. In cases where the GLD to be retreated exceeded the maximum spot size (approximately $6000 \mu \mathrm{m}$ during the TAP investigation), the treating ophthalmologist positioned the spot to encompass as much of the area of leakage as possible. ${ }^{32}$

Ninety four per cent of each group completed a follow up examination at 12 months. The proportion of verteporfin treated patients who required retreatment decreased with each follow up visit (91\% at month 3, 79\% at month $6,70 \%$ at month 9 , and $64 \%$ at month 12 ). The proportion of eyes with at least moderate vision loss (a decrease in the letter score of $\geqslant 15$ letters or approximately $\geqslant 3$ lines) was greater in placebo treated eyes than in verteporfin treated eyes throughout the period from examination at month 3 to the examination at month 12 (Fig 2). These visual acuity benefits were supported by numerous other outcomes. For example, the proportion of eyes with severe vision loss (a decrease in the letter score of $\geqslant 30$ letters or approximately $\geqslant 6$ lines) was greater in the placebo treated group than in the verteporfin treated group throughout this follow up. Verteporfin treated eyes were more likely to have a visual acuity better than $20 / 200$ at month 12 , and the mean number of contrast sensitivity letters lost was almost zero in the verteporfin treated eyes compared with about five letters in the placebo treated eyes.

In subgroup analysis based on the gradings of all fluorescein angiograms at a central photograph reading centre (Fig 3), the visual acuity benefit of verteporfin therapy was clearly demonstrated in eyes with classic CNV occupying at least $50 \%$ of the area of the entire lesion (termed "predominantly classic" lesions). With respect to predominantly classic lesions, $33 \%$ of the verteporfin treated eyes had at least moderate vision loss at 12 months compared with $60 \%$ of the placebo treated eyes (Fig 4). Furthermore, at this time, $12 \%$ of verteporfin treated eyes and $33 \%$ of placebo treated eyes had severe vision loss. ${ }^{32}$

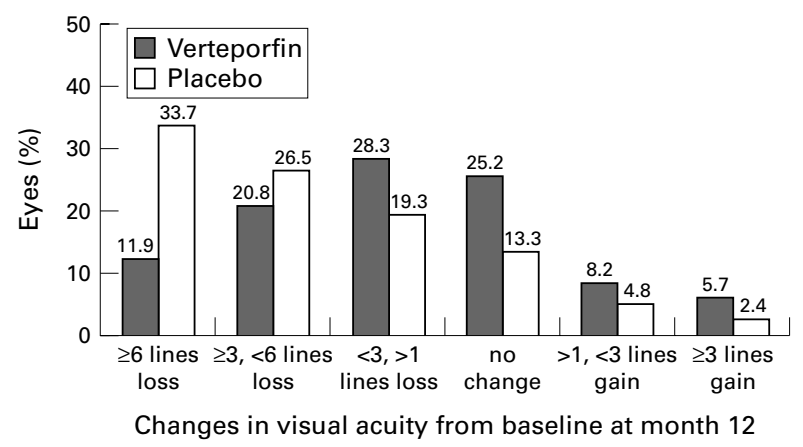

Figure 4 Distribution of changes in visual acuity from baseline at the month 12 examination of the TAP investigation for eyes with predominantly classic lesions.

The results were even greater for predominantly classic lesions and no occult CNV; $23 \%$ of verteporfin treated eyes had at least moderate vision loss at 12 months compared with $73 \%$ of placebo treated eyes. Ten per cent of the verteporfin treated eyes had severe vision loss compared with $41 \%$ of the placebo treated eyes. These results prompted the TAP Study Group to recommend verteporfin therapy for all predominantly classic lesions that met the eligibility criteria for the studies.

No statistically significant difference in visual acuity was noted when the area of classic CNV was greater than $0 \%$ but less than $50 \%$ of the area of the entire lesion (termed "minimally classic" CNV). There was a difference in favour of the verteporfin treated patients in the subgroup of lesions enrolled with no classic CNV. However, these cases should not have been enrolled because there was no evidence of classic CNV. Also, the number of patients in this subgroup was small: 37 patients treated with verteporfin and 19 patients given placebo had a follow up at month 12 . Therefore, no recommendation could be made at this time regarding treatment for this subgroup. These findings underscore the importance of identifying occult CNV, which is facilitated by stereoscopic frames and images obtained 5 and 10 minutes after fluorescein injection. Failure to recognise some occult $\mathrm{CNV}$ may result in overestimating the proportion of the lesion which is classic CNV or underestimating the GLD of the lesion and the spot size of the laser.

Several angiographic outcomes were consistent with the visual acuity outcomes. Progression of classic CNV beyond the area of the lesion identified at baseline occurred in only $166(46 \%)$ of 361 verteporfin treated eyes compared with $133(71 \%)$ of 187 placebo treated eyes by the month 12 examination. Placebo treated lesions were almost twice as likely $(73 \%)$ to be greater than 6 MPS disc areas in size than verteporfin treated lesions (40\%), even though most lesions in both groups were less than 6 MPS disc areas in size at baseline. Fluorescein leakage was absent from classic CNV in $68(19 \%)$ of the verteporfin treated eyes compared with $17(9 \%)$ of the placebo treated eyes. No major differences in angiographic outcomes of occult CNV were noted between the verteporfin and placebo groups. These results suggest that verteporfin therapy reduces lesion growth, is associated with cessation of leakage from classic $\mathrm{CNV}$, and decreases the likelihood of progression from classic CNV. Angiographic outcomes appeared to be better for lesions treated with verteporfin that had minimally classic CNV, even though a visual acuity benefit was not noted in this subgroup. This finding suggests that angiographic outcome cannot be used as the only surrogate outcome for the visual acuity benefits of verteporfin therapy for CNV in AMD.

Few ocular systemic adverse events judged to be of any clinical relevance were noted. Compared with placebo patients, verteporfin treated patients had more transient 
vision disturbances ( $18 \% v 12 \%)$, injection site adverse events $(13 \% v 3 \%)$, transient photosensitivity reactions $(3 \%$ $v 0 \%$, and infusion related low back pain $(2 \% v 0 \%)$. However, most of these events were mild to moderate, and discontinuation of treatment was rarely $(<2 \%$ of the time) requested by the ophthalmologist or study participant or both. These findings suggest that patients should be warned of mild, transient visual disturbances and that they need to return for follow up soon after treatment only if severe vision loss is noted. Infusion should be to the antecubital veins, whenever possible, to reduce risk of extravasation. If extravasation occurs in the antecubital fossa, it can be easily covered with long sleeved clothing. Furthermore, patients should realise that, although back pain may rarely occur during infusion, it causes no known long term problem and should be relieved as the infusion ends. Finally, avoiding direct sunlight or bright indoor light for the first 48 hours after treatment is probably sufficient if there is no extravasation.

In summary, the TAP investigation showed that verteporfin therapy reduced the risk of at least moderate vision loss compared with placebo for at least 12 months in patients with predominantly classic CNV who presented with subfoveal lesions. In the TAP investigation, the visual acuity results were complemented by similar outcomes for contrast sensitivity evaluations.

Recent reports suggest that the overall beneficial outcomes noted in the TAP investigation at 12 months remained the same at follow up examinations up to 24 months, with $41 \%$ of verteporfin treated eyes compared with $69 \%$ of placebo treated eyes having at least moderate visual acuity loss at the month 24 examination for predominantly classic lesions. Thus, the 2 year results provide further support to recommend verteporfin therapy in the management of patients with predominantly classic subfoveal CNV due to AMD.

\section{Other treatments currently under investigation}

The following treatments are still under investigation; no proved benefit has yet been demonstrated in large scale randomised clinical trials.

\section{REFINEMENTS OF PHOTOCOAGULATION}

Many patients with neovascular AMD probably present with occult $\mathrm{CNV}$ without classic $\mathrm{CNV} .{ }^{18}$ In the past few years, a number of therapeutic techniques have been investigated for this type of CNV, but none has shown convincing evidence of efficacy.

Improvement in diagnosis

CNV often has poorly defined boundaries on fluorescein angiography. Indocyanine green (ICG) angiography may improve the visualisation of these lesions. Accurate delineation and localisation with ICG angiography can allow some of these lesions to be superimposed over a red-free photograph or on early phase fluorescein angiograms. This approach may result in ICG guided laser photocoagulation treatment of lesions with poor definition on fluorescein angiography that are well defined and do not involve the fovea on ICG angiography. These lesions would not be eligible for treatment under MPS guidelines; thus, a combination of fluorescein and ICG angiography might allow more eyes with CNV due to AMD to be treated.

The results from a limited number of small, uncontrolled studies evaluating laser photocoagulation guided by ICG angiography have shown that there is complete resolution of fluid and other clinical manifestations of CNV in some eyes with occult CNV. Furthermore, some of these eyes showed improvement or stabilisation of visual acuity.
Similar results have been obtained for laser photocoagulation of focal spots at the edge of plaques of subfoveal occult CNV. ${ }^{57}$ The same approach has been considered for CNV associated with RPE detachment. In one pilot study, ICG guided laser photocoagulation temporarily stabilised visual acuity in some eyes but final visual acuity decreased with time. ${ }^{58}$ These results should be compared with the natural history outcomes of these lesions to establish if they differ from those seen without treatment. ${ }^{59}$

Because of the light absorption peak of the ICG dye, some authors considered the use of ICG enhanced diode laser photocoagulation. This approach was thought to permit a selective removal of ICG stained CNV with relative sparing of the neighbouring neurosensory retina. Limited groups of patients showed potential benefits in small, uncontrolled studies. ${ }^{60}$ However, little difference was demonstrated between ICG enhanced and non-enhanced mild diode laser burns and thus this approach has still to demonstrate its efficacy.

Some investigators have claimed that other approaches based on ICG angiography are successful. Various techniques using either dynamic or high speed videoangiography have been used to visualise extrafoveal feeder vessels of subfoveal CNV that would not benefit from laser photocoagulation. These techniques have been used in conjunction with fluorescein angiography, but results were not reproducible because it was not always possible to distinguish arterial and venous feeder vessels. With very early phase ICG angiography, arterial feeder vessels can be distinguished from the draining veins. Photocoagulation of the feeder vessels is performed with argon green laser $^{61}$ (Fig 5), dye laser, ${ }^{62}$ or diode or micropulse diode laser. According to the results of small, uncontrolled studies this technique based on ICG angiography may decrease fluid and thus allow improvement in visual acuity.

Improvement in photocoagulation techniques

The destruction of the neurosensory retina overlying the $\mathrm{CNV}$ has always been a concern with laser photocoagulation. In order to minimise the destruction, and even spare the photoreceptors, selective photocoagulation has been attempted. Multiple short argon laser pulses of a green Nd:YLF laser ${ }^{63}$ or repetitive short micropulses of a diode laser $(710 \mathrm{~nm})$ have been shown histologically to reduce damage to the photoreceptors and to allow the replacement of the original RPE by a monolayer of new RPE cells. In addition, a minimal inflammatory response was observed with these techniques. This approach for the treatment of macular diseases is at present under evaluation in small, uncontrolled studies. ${ }^{64}$

\section{Transpupillary thermotherapy}

Transpupillary thermotherapy is a technique by which heat is delivered to the choroid and RPE using a diode laser at $810 \mathrm{~nm}$. This therapy has been reported to be effective for choroidal melanomas. ${ }^{65}$ The goal in using this technique for treatment of $\mathrm{CNV}$ is to achieve occlusion of the neovascularisation without damage to other cells. Heat penetration is optimised by exposure time, beam diameter, and wavelength. In addition, inner retinal effects produced by coagulation are absent, thus optimising the penetration of the light. Transpupillary thermotherapy may also minimise collateral damage to the adjacent normal retina due to delivery of decreased thermal energy.

A retrospective study with a limited number of cases and limited follow up without controls evaluated 16 eyes presenting with subfoveal occult $\mathrm{CNV}$ on fluorescein angiography. ${ }^{66}$ The spot size was adapted to the size of the $\mathrm{CNV}$, and the power ranged between 360 and $1000 \mathrm{~mW}$ for 60 seconds. The end point was an area of no visible 

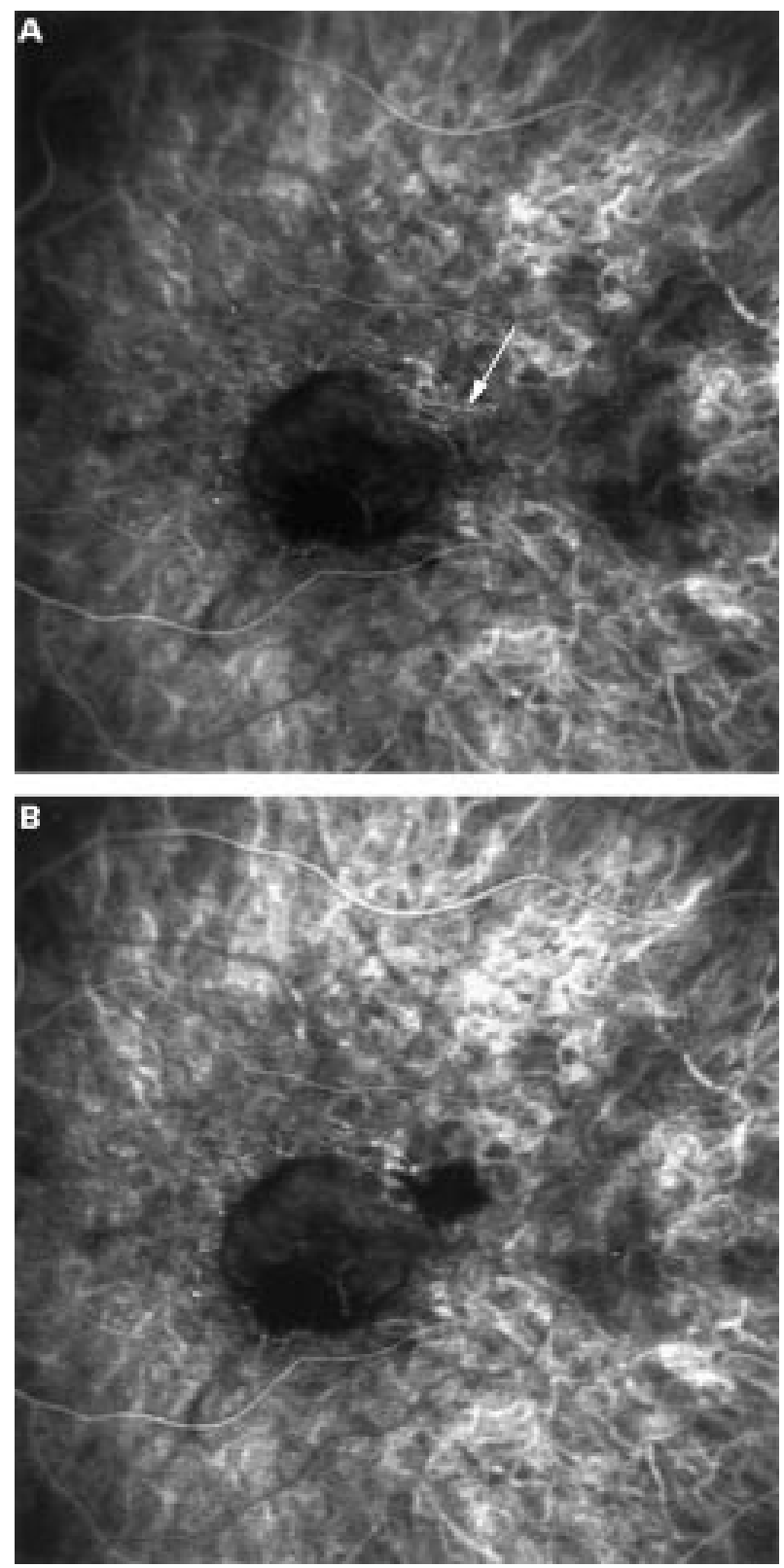

Figure 5 ICG guided feeder vessel photocoagulation. Very early phase ICG angiography at presentation (A) of patient with subfoveal occult $C N V$ and visual acuity of 20/40. The early photographs show a horizontal choroidal vessel (arrow), intensely hyperfluorescent at the arterial choroidal phase, located in the superotemporal part of the posterior pole, outside of the foveal avascular zone. This vessel was considered to be the arterial feeder vessel of the CNV because it was only perfused for 3 seconds of the arterial phase, and was no longer visible thereafter. Furthermore, its perfusion was pulsatile, and its flow was in the opposite direction to that in the normal choroidal artery. The vessels below the feeding vessel were filling subsequently. Early phase of ICG angiography (B) immediately after focal laser photocoagulation of the feeder vessel shows hypofluorescence of the laser treated area superotemporal to the hypofluorescence of the neovascular lesion of the feeder vessel identified.

colour change to a light grey appearance of the level of the pigment epithelium. In this study, visual acuity remained stable in nine eyes $(56 \%)$, while three eyes $(19 \%)$ showed two lines of improvement, and four eyes $(25 \%)$ a decrease of two lines or more during a mean follow up period of 12 months. The authors reported that most eyes (94\%) demonstrated a decreased exudation on clinical examination, fluorescein angiography, and optical coherence tomography. The value of this therapeutic approach would require comparison with controls in randomised clinical trials.
SUBMACULAR SURGERY

A variety of surgical techniques have been investigated for the treatment of subfoveal CNV secondary to AMD. The risks and benefits, which still remain imprecise, are under investigation in the USA in randomised clinical trials sponsored by the National Eye Institute of the National Institutes of Health. ${ }^{67}$ These trials include eyes with subretinal haemorrhage that is too extensive to allow laser photocoagulation or photodynamic therapy, as well as eyes with some classic CNV (but not necessarily predominantly classic lesions) and an initial visual acuity of 20/100 to 20/800.

Removal of CNV by submacular surgery is through a small retinotomy and may therefore minimise injury to the overlying photoreceptors. ${ }^{68}$ However, histological examination shows that CNV removed by this technique often contains photoreceptors and RPE cells, and thus explains why submacular surgery in AMD usually results in a central scotoma. ${ }^{69-72}$ Retinal detachment or postoperative cataract may also occur secondary to this surgical procedure. ${ }^{69}$

Most studies investigating submacular surgery have shown that submacular excision of CNV does not improve mean vision in patients with AMD. ${ }^{69}{ }^{73}$ In the largest prospective study in patients undergoing excision of subfoveal CNV, mean visual acuity 12 months after surgery was $20 / 320$ with a mean loss in visual acuity of one line compared with baseline. ${ }^{74}$ As with laser photocoagulation, recurrence of $\mathrm{CNV}$ may be common following submacular surgery, as suggested by the results of Thomas et al, showing a recurrence rate of $46 \%$ in eyes that were followed up for a period of 12 months or more. ${ }^{75}$ The reasons for poor vision outcomes after submacular surgery potentially include irreversible damage to the photoreceptors or RPE, caused either by the subfoveal CNV or by partial removal of these structures by the surgical technique, and retinal damage mediated by subretinal fibrin. ${ }^{73}$ The use of tissue plasminogen activator before CNV excision did not provide any vision or anatomical benefit in a randomised double masked trial. ${ }^{74}$

Despite these limitations, submacular surgery may increase the chance for stable or slightly improved vision in selected patients with new subfoveal lesions with evidence of classic CNV that otherwise might progress to a large amount of vision loss if left untreated. This is being investigated in a randomised clinical trial, (Group N Protocol) Submacular Surgery Trials (SST) sponsored by the National Eye Institute. ${ }^{67}$ Submacular surgery also might be beneficial compared with no surgery for patients who present with large submacular haemorrhages due to CNV in which the large amount of blood precludes use of laser for photocoagulation or photodynamic therapy. This is being investigated in another SST protocol, Group B. Both protocols are designed to study whether submacular surgery would increase the likelihood of vision stabilisation or improvement, compared with no surgery. These studies are ongoing, and no results have yet been published.

OTHER SURGICAL TECHNIQUES

Other surgical techniques include RPE transplantation and macular translocation of subfoveal classic CNV. Macular translocation has been developed to rotate the retina and therefore move the foveal region away from the $\mathrm{CNV}^{76-79}$ After a $360^{\circ}$ retinotomy, improvement in distance vision was obtained in only $10 \%$ of the patients in published reports-about half of these patients experienced an improvement in reading vision. ${ }^{77}{ }^{78}$ Postoperative complications with this technique include the development of retinal detachment, macular pucker, increased lens opacity in the phakic eyes, and disorienting side effects of diplopia and tilted image that might be managed with 

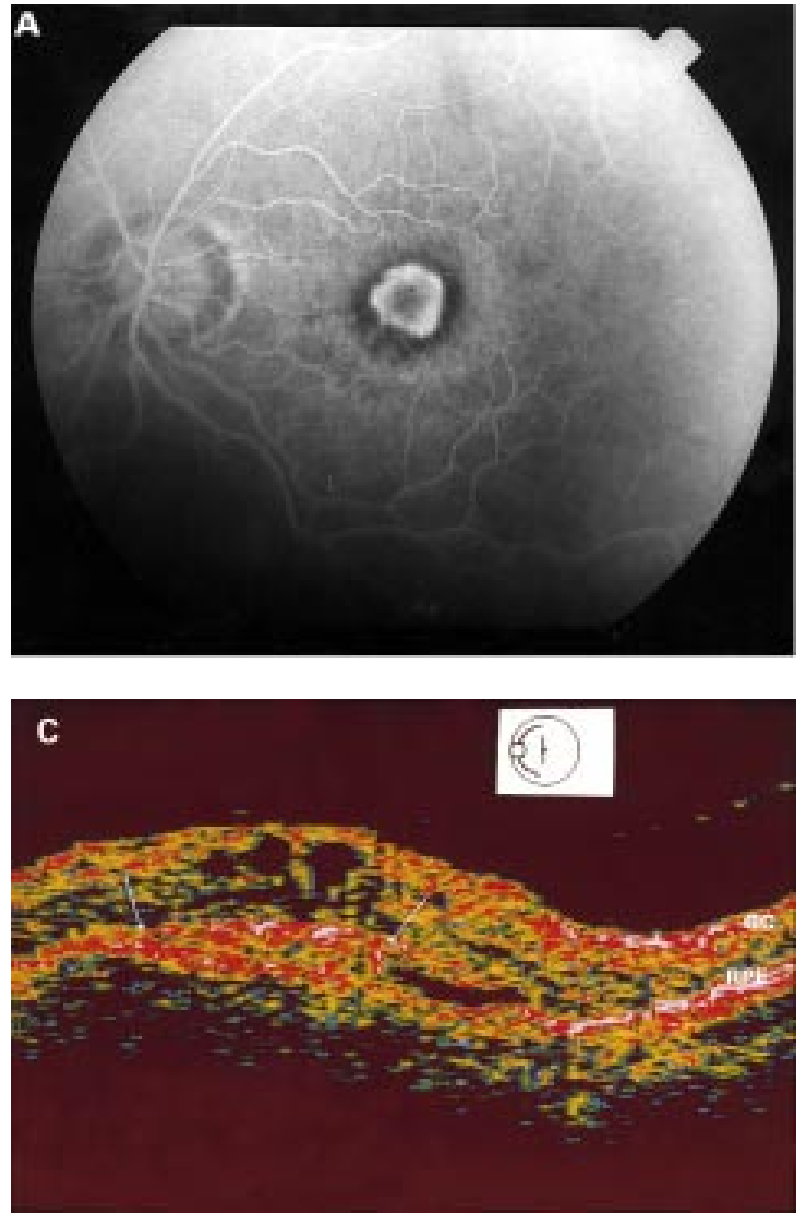

Figure 6 Limited foveal translocation. Fluorescein angiography at presentation (A) shows a small well defined foveal lesion involving the entire avascular zone. ICG angiography (B) discloses the subfoveal classic lesion in the same location as fluorescein angiography. OCT imaging (C) shows the normal hyperreflectivity of the ganglion cell layer in the inner retina (GC) and of the outer complex of retinal pigment epithelium, Bruch's membrane, and choriocapillaris (RPE). This later hyperreflectivity is a continuous layer, but a mushroom outgrowth is extending into the neurosensory retina (arrows). This aspect appears to correspond to the well defined choroidal lesion. ICG angiography (D) performed after surgically limited translocation and photocoagulation of the classic CNV shows that the laser treated area now lies next to the superotemporal retinal artery, outside of the fovea which is located away from the photocoagulated area (circle).

muscle surgery. ${ }^{77}$ A potentially less damaging technique consists of performing a shortening of the sclera combined with a retinal detachment allowing a more limited (1-2 $\mathrm{mm}$ ) translocation of the macula. ${ }^{79}$ The application of laser photocoagulation, after macular translocation, to the CNV that is no longer subfoveal may avoid subsequent immediate vision loss (Fig 6) ${ }^{79}$ Published reports of this technique has only been investigated in a small number of patients. The results from the first three patients indicated vision improvement in about $40-60 \%$ of the eyes. Translocation of the RPE, from the edge of the RPE defect to a subfoveal location, following submacular removal of CNV, has also been suggested recently as a new approach to the surgical management of neovascular AMD. ${ }^{80}$

RPE transplantation might be used after removal of subfoveal CNV to replace destroyed or degenerated RPE to improve visual function. ${ }^{81}$ This therapeutic approach started as a form of intraocular grafting performed by Gouras et al in 1984 by placing human xenografts into monkey eyes. ${ }^{82}$ In animal models receiving human xenografts, retinal function has been maintained at the transplantation site for long periods. ${ }^{81}{ }^{83}$ Several anatomical and functional tests have suggested that fetal retinal cells
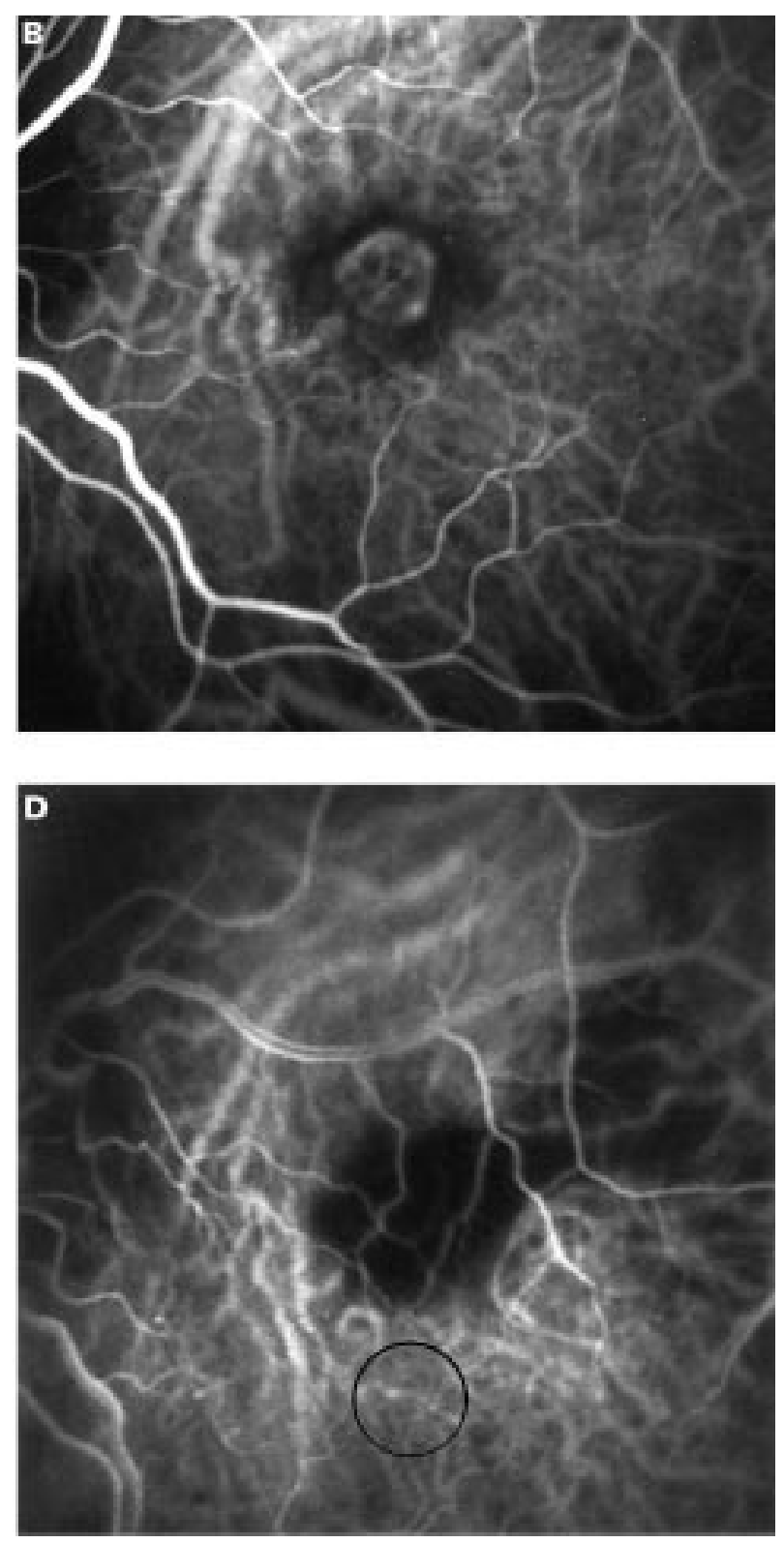

give the best results in the host retina. ${ }^{83}$ However, the survival of these cells might be affected by age and RPE depigmentation..$^{83} \mathrm{RPE}$ transplantation needs to be conducted at an early stage of the degenerative process so that the rescue effect on degenerative photoreceptor cells can be obtained. ${ }^{83}$

In neovascular AMD, transplantation of RPE allografts into the submacular space after surgical removal of CNV can lead to macular oedema, chronic fluorescein leakage around the transplant, and gradual reduction of visual acuity. This is attributed to host-graft rejection of the transplanted material, which may require regional immunosuppression at the site of transplantation..$^{81}{ }^{83}$ Subretinal transplantation has also been performed using cell suspensions containing autologous pigment epithelium collected from the human iris before surgery. The results of this technique are not yet known in humans. In the rabbit, although these cells have proved capable of phagocytosis, ${ }^{84}$ their full metabolic capacity still remains to be elucidated.

Current uncontrolled clinical trials are investigating the potential benefits and complications following transplantation of human fetal neuroretinal cells in patients blinded by 
retinitis pigmentosa. ${ }^{83}{ }^{85}$ Results of these studies have suggested that this technique may be less immunogenic, although no convincing evidence of functionality in the host eye has been found. ${ }^{85}$

In AMD, however, the photoreceptors and RPE are either damaged or destroyed, and thus a graft of the two layers into the damaged macula may be required. Another possibility is the use of the diffusible trophic factor released from normal rods, which has been shown to stimulate cone survival in degenerated retinas. ${ }^{86}$ This factor still needs to be identified and isolated.

Research has been carried out into the feasibility of by passing damaged photoreceptors and electrically stimulating the remaining viable retinal layers to provide limited visual input to patients who are visually impaired because of severe photoreceptor degeneration. A large number of experimental studies have been performed using either subretinal $^{87-89}$ or epiretinal ${ }^{90}$ implanted electronic devices. In experimental models, electrophysiological recording has demonstrated the possibility of electrical stimulation of the inner retina. Histologically, subretinal implants result in a significant loss of retinal cells in areas overlying the implant, while the retina at a distance from the implant and from the surgical site remains normal. ${ }^{88}$

Some short duration attempts have been performed in the operating room on five patients under local anaesthetic. Local electrical stimulation of the retinal surface resulted in focal light perception that seemed to arise from the stimulated area. ${ }^{91}$ However, the perception of a spot of light is still a very early stage compared with the perception of shapes. A number of issues still remain to be addressedlocalisation of the implant (subretinal or epiretinal), stability of the position of the implant, biocompatibility and the possibility of central fixation, and long term results are awaited.

\section{RADIATION THERAPY}

The rationale of radiation therapy is to deliver a precise dose of ionising radiation to a defined area to inhibit neovascularisation within that area, without causing damage to surrounding healthy tissue. ${ }^{92}$ The mechanism through which ionising radiation inhibits the formation and growth of new vessels has not yet been fully elucidated. Radiation therapy has its major application in the treatment of malignant tumours and intraocular tumours, ${ }^{93}$ and has been investigated as a potential treatment for AMD since the early 1990 s. $^{94}$

In clinical trials, either external beam therapy, also called teletherapy, or brachytherapy is used to treat AMD. The first method involves the use of a clinical linear accelerator that produces a high energy $x$ ray beam delivered to the portion of the eye to be treated. The second method uses sealed radioactive sources that are placed directly into, or adjacent to, the area to be treated..$^{92}$ Radiation therapy could be applicable to eyes with CNV not amenable to laser photocoagulation, because it is non-invasive, has no effect on the neurosensory retina, and can be conducted with precision..$^{95}$

The optimal total dose of radiation therapy, fractionation schedule, and method of delivery have not yet been fully elucidated, ${ }^{92}{ }^{95-97}$ and preliminary results suggest that multiple treatments may be necessary for an effective total dose. $^{92}$ In short term uncontrolled studies, radiation therapy has been reported to stabilise visual acuity and cause regression of subfoveal CNV..$^{92}{ }^{94}$ In patients with occult $\mathrm{CNV}$ and no classic $\mathrm{CNV},{ }^{98}$ this technique has been shown to stabilise visual acuity and angiographic choroidal neovascular lesion size in 28 eyes at 6 and 9 month follow up. ${ }^{99}$ However, recent longer term studies in larger numbers of patients with neovascular AMD have shown that external beam radiation therapy does not control the growth of $\mathrm{CNV}^{95}$ or have beneficial effects on visual acuity. ${ }^{96}$ A recent report from a randomised, controlled, double blind study indicated that teletherapy provided no benefits in terms of visual acuity in 178 patients with AMD related CNV at 1 year follow up, ${ }^{100}$ even though a smaller randomised clinical trial had suggested some benefit. ${ }^{101}$

Although visual acuity improvement has been suggested to be dose related, ${ }^{95}{ }^{96}$ there is no convincing evidence that high dose irradiation leads to a beneficial visual acuity effect at this time. ${ }^{95}$ Furthermore, high doses of irradiation have been associated with the risk of optic neuropathy, and retinal and choroidal vasculopathy (Fig 7). ${ }^{95}$ In addition, radiation retinopathy may develop in a 6 month to 3 year period with teletherapy, but tends to occur sooner with brachytherapy. ${ }^{95}$ Extra caution should be taken with radiation therapy in case of potential concomitant retinal vascular disease such as in patients with diabetes mellitus.

\section{ANTIANGIOGENIC THERAPY}

To date, the findings from clinical studies with antiangiogenic drugs have not been encouraging. ${ }^{23}$ A randomised, placebo controlled, multicentre trial of systemic interferon alfa-2a has shown that the therapy for CNV secondary to $\mathrm{AMD}$ is not beneficial and may even be harmful. ${ }^{102}$ Such a specific treatment may be ineffective because of the variety of factors that are involved in angiogenesis.

Other pharmacological agents which have been suggested as potential antiangiogenic drugs for the treatment of neovascular AMD include retinoids, corticosteroids, triamcinolone acetate, thalidomide, matrix metalloproteinase inhibitors, and apoptotic agents. ${ }^{23}{ }^{103-107}$ Most of these agents have only been studied in animal models: a few of these drugs have been evaluated in small clinical trials. In an animal model of corneal neovascularisation, thalidomide administered orally and intraperitoneally effectively inhibited angiogenesis. ${ }^{103} 108$ The clinical safety of thalidomide in the treatment of neovascular AMD is currently under investigation. ${ }^{109}$ Among the latter antiangiogenic agents, isotretinoin, a retinoid, has not shown any significant effect, whereas others await further larger scale clinical trials to confirm their effects. ${ }^{23}$

Several growth factors that have been shown to contribute to the molecular events involved in the regulation of blood vessel growth may play an important part in the pathogenesis of CNV. These include vascular endothelial growth factor (VEGF), transforming growth factor $\beta$, platelet derived growth factor, and basic fibroblast growth factor. $^{23}$ VEGF, in particular, has stimulated much research interest. ${ }^{110-113}$ These growth factors are not expressed at levels detectable by immunochemistry in normal RPE cells, but show an increased expression in AMD, suggesting a pathogenic role in CNV growth. ${ }^{110}$

It has been suggested that basic fibroblast growth factor and VEGF act synergistically to accelerate neovascularisation, and that upregulation of VEGF is stimulated by hypoxia, which is possibly a pathogenic factor in CNV secondary to AMD. ${ }^{110-112}$ This hypothesis is further strengthened by the findings from a study in 164 patients undergoing intraocular surgery showing that VEGF concentrations are elevated in those patients with active intraocular neovascularisation. ${ }^{111}$ Inhibitors of VEGF have been identified in studies conducted in vitro and in animal models, and include VEGF antagonists and suppressants, and inhibitors of the VEGF intracellular transduction cascade. ${ }^{23}{ }^{111}$ Clinical research will confirm whether growth factors are better targets for antiangiogenic therapies in the future. 

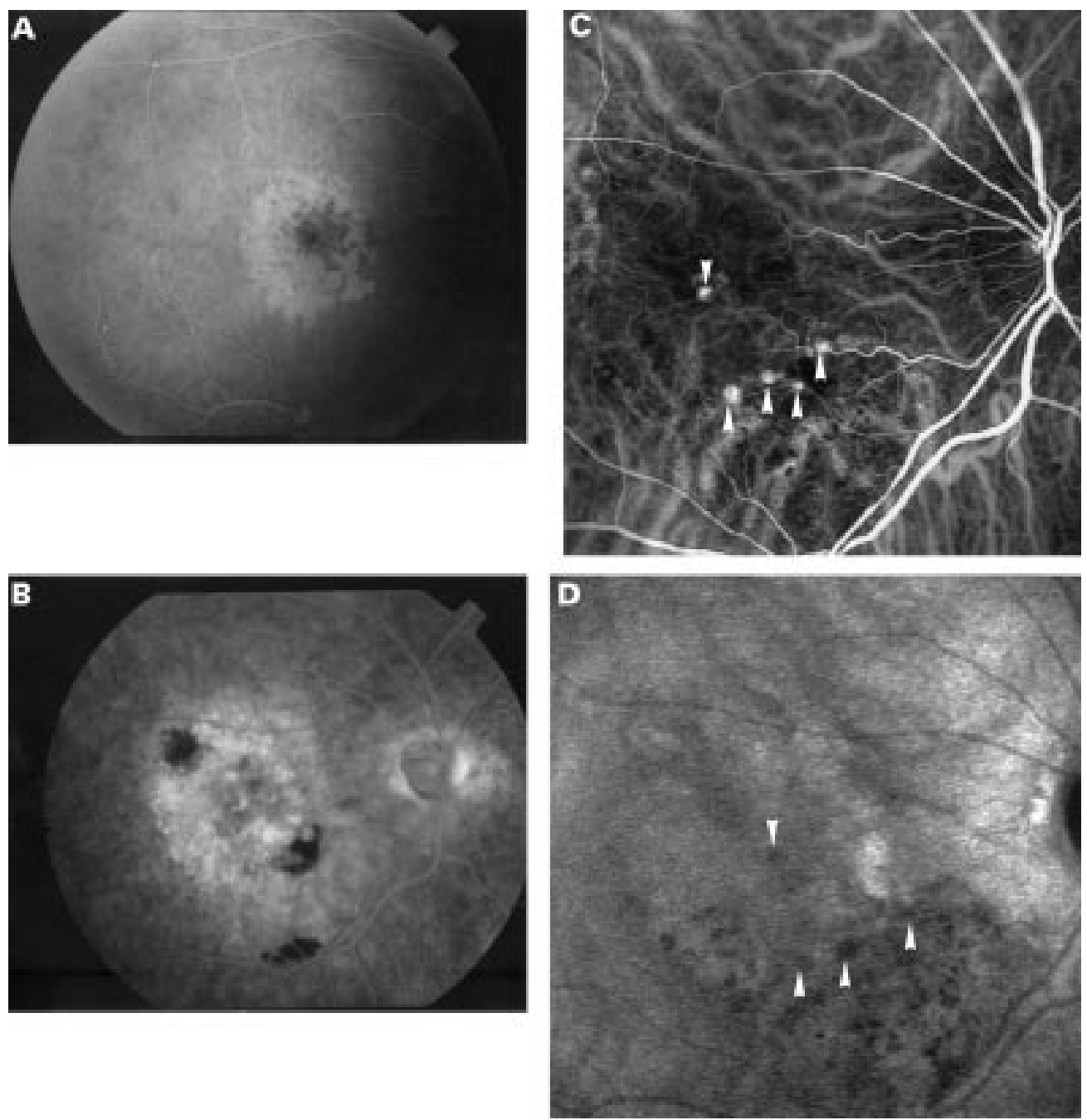

Figure 7 Radiation therapy for subfoveal occult CNV. Early phase fluorescein angiogram at presentation $(A)$ shows small adjacent areas of hyperfluorescence and hypofluorescence involving the whole macula. Late phase fluorescein angiogram 1 month later (B) shows active occult new vessels with occurrence of retinal haemorrhage and subfoveal fluorescein leakage 2.5 MPS disc areas in size. No laser photocoagulation treatment could be considered and thus the patient was submitted to radiation therapy. Early phase ICG angiogram (C) performed 14 months after treatment demonstrates five areas of round, hyperfluorescent choroidal dilatation disseminated on the border of the remaining lesion (arrowheads). Later phase ICG angiogram (D) discloses the washout of some of the hyperfluorescent bulges (arrowheads)

OTHER STUDIES USING PHOTODYNAMIC THERAPY WITH VERTEPORFIN

A phase IIIB investigation, the Verteporfin In Photodynamic Therapy (VIP) Trial should provide further understanding of the benefits of verteporfin therapy in eyes with $\mathrm{CNV}$ that were not included in the TAP investigation. This trial includes a large proportion of eyes with subfoveal CNV secondary to AMD containing an occult component but no classic component. Patients were enrolled with subfoveal occult CNV secondary to AMD associated with haemorrhage or visual acuity deterioration within the past 3 months ( $\geqslant 1$ line loss), or evidence of anatomical growth of the neovascular lesion within the past 3 months (an increase of $10 \%$ or more of the GLD on fluorescein angiography). In addition, the VIP Trial enrolled patients with subfoveal CNV secondary to AMD that had a classic component, if the visual acuity was better than that in patients enrolled in the TAP investigation (specifically, better than 20/40). Since the results from the phase I/II investigation suggested that verteporfin therapy might be beneficial in subfoveal CNV secondary to pathologic myopia, ${ }^{56}$ patients with this type of lesion were also enrolled in the VIP trial. Recent results reported that the therapy was beneficial for subfoveal lesions caused by pathological myopia. ${ }^{114}$ However, no statistically significant difference for the primary outcome ( $<15$ letter loss at the month 12 examination) was reported for the subgroup of patients with AMD with occult CNV but no classic CNV at baseline.

PHOTODYNAMIC THERAPY WITH OTHER PHOTOSENSITISERS A number of other photosensitisers are being developed for the treatment of AMD. For example, lutetium texaphyrin (Lu-Tex) is a water soluble photosensitiser with an absorption peak at $730 \mathrm{~nm} .{ }^{115}$ Studies in a tumour model in mice have shown that the optimum time of irradiation may be 24-48 hours after injection of the photosensitiser. ${ }^{115}$ In an experimental monkey model, cessation of fluorescein leakage from CNV was obtained with $1-2 \mathrm{mg} / \mathrm{kg}$ body weight of Lu-Tex and a light irradiation dose of $50-100 \mathrm{~J} / \mathrm{cm}^{2} .{ }^{116}$ At these doses there is limited toxicity to retinal and choroidal structures. Lu-Tex is currently in phase I clinical trials which evaluate the safety of this compound for patients with subfoveal CNV.

Tinethyl etiopurpurin (SnET2) is activated by low energy $664 \mathrm{~nm}$ red light. Preliminary work with this photosensitiser includes photodynamic therapy of corneal neovascularisation in rats and in rabbits. ${ }^{117}$ The activating light can be administered 5-20 minutes after SnET2 injection to cause effective occlusion of choroidal capillaries. In phase I/II trials conducted in 28 patients with subfoveal 
CNV, photodynamic therapy with SnET2 $(0.5-1.0 \mathrm{mg} / \mathrm{kg}$ body weight) resulted in cessation of leakage of fluorescein from CNV associated with improvement in visual acuity in $89 \%$ of 28 eyes within 1 week of treatment. ${ }^{118}$ Fluorescein leakage was noted in $64 \%$ of the eyes 12 weeks after initial treatment. Longer term visual acuity effects of this treatment were investigated in a subsequent study, in which 14 eyes were treated with $0.25-1.0 \mathrm{mg} / \mathrm{kg}$ body weight of SnET2 using a light dose of $35 \mathrm{~J} / \mathrm{cm}^{2}{ }^{219}$ At the 6 month follow up examination, visual acuity declined by 1.1 lines in $50 \%$ of the treated eyes. Patients are currently being enrolled in a phase III trial to determine if this treatment can reduce the risk of visual acuity loss compared with placebo.

Mono-L-aspartyl chlorin e6 (NPe6) is a hydrophilic photosensitiser, which is activated at $664 \mathrm{~nm}$ and has been shown to selectively occlude experimentally induced CNV in primates. ${ }^{120}$ As a hydrophilic agent, NPe6 is supposed to have the advantages of having limited extravascular uptake and rapid elimination. Consequently, the duration of skin photosensitivity will be shorter with this agent than with HPD. ${ }^{121}$

\section{Conclusions}

Because the prevalence of AMD is associated with age, its socioeconomic implications are becoming more important as the proportion of older people increases in developed countries. However, AMD not only affects people in the older age groups; people over 50 years of age, who are still relatively young and may still be active, are also at an increased risk of acquiring the disease.

No preventive treatment exists for neovascular AMD, the form of AMD that is responsible for severe vision loss, although two approaches are under investigation, including micronutrient use (Age Related Eye Disease Study) ${ }^{122}{ }^{123}$ and light laser photocoagulation (Complications of Age Related Macular Degeneration Prevention Trial). ${ }^{124}$ If left untreated, neovascular AMD will usually result in a poor vision outcome. During the 1990s, laser photocoagulation was used to treat neovascular AMD, but it can only benefit a small proportion of selected cases. Other therapies, such as surgery, radiation therapy, and antiangiogenic therapy, are under investigation.

Photodynamic therapy is a proved treatment modality for certain eyes with subfoveal CNV secondary to AMD. Compared with other light activated drugs, verteporfin is at the most advanced developmental stage. Phase III data from 12 and 24 months demonstrate that verteporfin therapy is safe, with few systemic side effects and no prolonged skin photosensitivity, and that verteporfin therapy reduces the risk of vision loss in subfoveal cases with predominantly classic CNV. Verteporfin therapy does not repair irreversibly damaged tissue but might prevent further growth of CNV as suggested by fluorescein angiography. Verteporfin therapy became available in early 2000 as the first drug therapy for patients with subfoveal neovascular AMD.

Several new treatment opportunities may be afforded by verteporfin therapy because this new treatment modality, without the destructive effects on the neurosensory retina seen with laser photocoagulation, can be of benefit to a greater number of patients with subfoveal lesions compared with photocoagulation. The results from current clinical investigations will confirm whether verteporfin therapy is useful in the treatment of a wide range of cases of subfoveal CNV due to AMD with occult CNV but no classic CNV and cases with CNV due to non-AMD causes, such as pathological myopia.
The authors thank all the members of the TAP Study Group, whose names and affiliations are listed in the following reference: Treatment of Age-related Macular Degeneration With Photodynamic Therapy (TAP) Study Group. Photodynamic therapy of subfoveal choroidal neovascularization in age-related macular degeneration with verteporfin. One-year results of 2 randomized clinical trialsTAP Report 1. Arch Ophthalmol 1999;117:1329-45.

GISÈLE SOUBRANE

Clinique Ophtalmologique Universitaire de Créteil, Université

Paris-Val-de-Marne, Créteil, France

NEIL M BRESSLER

The Wilmer Ophthalmological Institute, Johns Hopkins University School of Medicine, Baltimore, MD, USA

1 Bird AC, Bressler NM, Bressler SB, et al. An international classification and grading system for age-related maculopathy and age-related macular degeneration. The International ARM Epidemiological Study Group. Surv Ophthalmol 1995;39:367-74.

2 Gass JDM. Pathogenesis of disciform detachment of the neuroepithelium. III. Senile disciform macular degeneration. Am f Ophthalmol 1967;63:61764 .

3 Loewenstein A, Bressler NM, Bressler SB. Epidemiology of RPE disease. In: Marmor MF, Wolfensberger TJ, eds. Retinal pigment epithelium: current aspects of function and disease. New York: Oxford University Press, 2000.

4 Holz FG, Wolfensberger TJ, Piquet B, et al. Bilateral macular drusen in agerelated macular degeneration. Prognosis and risk factors. Ophthalmology 1994;101:1522-8.

5 Macular Photocoagulation Study Group. Laser photocoagulation of subfoveal neovascular lesions of age-related macular degeneration. Updated findings from two clinical trials. Arch Ophthalmol 1993;111:12009.

6 Green WR, Enger C. Age-related macular degeneration histopathologic studies. The 1992 Lorenz E Zimmerman Lecture. Ophthalmology studies. The 1992

7 Green WR, Key SN. Senile macular degeneration: a histopathologic study. Trans Am Ophthalmol Soc 1977;75:80-254

8 Ferris III FL, Fine SL, Hyman L. Age-related macular degeneration and blindness due to neovascular maculopathy. Arch Ophthalmol 1984;102: 1640-2.

9 Submacular Surgery Trials Research Group. Submacular surgery trials. Manual of procedures. Springfield, VA: National Information Service Accession No PB98 166648, 1998.

10 Bressler NM, Bressler SB, Fine SL. Age-related macular degeneration. Surv Ophthalmol 1988;32:375-413.

11 Kahn HA, Leibowitz HM, Ganley JP, et al. The Framingham Eye Study. I. Outline and major prevalence findings. Am 7 Epidemiol 1977;106:17-32.

12 Bressler NM, Bressler SB, West SK, et al. The grading and prevalence of macular degeneration in Chesapeake Bay watermen. Arch Ophthalmol 1989;107:847-52.

13 Klein R, Klein BEK, Linton KLP. Prevalence of age-related maculopathy. The Beaver Dam Eye Study. Ophthalmology 1992;99:933-43.

14 Mitchell P, Smith W, Attebo K, et al. Prevalence of age-related maculopathy in Australia. The Blue Mountains Eye Study. Ophthalmology 1995;102: $1450-60$.

15 Vingerling JR, Dielemans I, Hofman A, et al. The prevalence of age-related maculopathy in the Rotterdam Study. Ophthalmology 1995;102:205-10.

16 Pizzarello LD. The dimensions of the problem of eye disease among the elderly. Ophthalmology 1987;94:1191-5.

17 Evans J, Wormald R. Is the incidence of registrable age-related macular degeneration increasing? Brf Ophthalmol 1996;80:9-14.

18 Freund KB, Yannuzzi LA, Sorenson JA. Age-related macular degeneration and choroidal neovascularization. Am $\mathcal{f}$ Ophthalmol 1993;115:786-91.

19 Moisseiev J, Alhalel A, Masuri R, et al. The impact of macular photocoagulation study results on the treatment of exudative age-related macular degeneration. Arch Ophthalmol 1995;113:185-9.

20 Bressler NM, Bressler SB, Gragoudas ES. Clinical characteristics of choroidal neovascular membranes. Arch Ophthalmol 1987;105:209-13.

21 Berkow JW. Subretinal neovascularization in senile macular degeneration. Am f Ophthalmol 1984;97:143-7.

22 Soubrane G, Coscas G. Experimental therapies for age-related macular degeneration. Dev Ophthalmol 1997;29:78-84.

23 Ciulla TA, Danis RP, Harris A. Age-related macular degeneration: a review of experimental treatments. Surv Ophthalmol 1998;43:134-46.

24 Macular Photocoagulation Study Group. Risk factors for choroidal neovascularization in the second eye of patients with juxtafoveal or subfoveal choroidal neovascularization secondary to age-related macular degeneration. Arch Ophthalmol 1997;115:741-7.

25 Coscas G, Glaser B, Green WR, et al. Dégénerescences maculaires liées à l'âge et néovaisseaux rétiniens. Paris: Masson, 1991:447.

26 Coscas G, Soubrane G. Photocoagulation des neovaisseaux sous-retiniens dans la degenerescence maculaire senile par laser a argon: resultats de l'etude randomisee de 60 cas. Bull Mem Soc Fr Ophtalmol 1983;94:149-54.

27 Macular Photocoagulation Study Group. Argon laser photocoagulation for neovascular maculopathy. Five-year results from randomized clinical trials. neovascular maculopathy. Five-year
Arch Ophthalmol 1991;109:1109-14.

28 Macular Photocoagulation Study Group. Laser photocoagulation for juxtafoveal choroidal neovascularization. Five-year results from randomized clinical trials. Arch Ophthalmol 1994;112:500-9.

29 Macular Photocoagulation Study Group. Visual outcome after laser photocoagulation for subfoveal choroidal neovascularization secondary to age-related macular degeneration. The influence of initial lesion size and initial visual acuity. Arch Ophthalmol 1994;112:480-8.

30 Coscas G, Soubrane G, Ramahefasolo C, et al. Perifoveal laser treatment for subfoveal choroidal new vessels in age-related macular degeneration. Results of a randomized clinical trial. Arch Ophthalmol 1991;109:1258-65.

31 Grey RHB, Bird AC, Chisholm IH. Senile disciform macular degeneration: features indicating suitability for photocoagulation. Br f Ophthalmol 1979; 63:85-9. 
32 Treatment of Age-related Macular Degeneration With Photodynamic Therapy (TAP) Study Group. Photodynamic therapy of subfoveal choroi(In age-related macular degeneration with verteporfin. One-year results of 2 randomized clinical trials-TAP Report 1. Arch Ophthalmol 1999;117:1329-45.

33 Manyak MJ, Russo A, Smith PD, et al. Photodynamic therapy. F Clin Oncol 1988;6:380-91.

34 Husain D, Miller JW. Photodynamic therapy of exudative age-related macular degeneration. Sem Ophthalmol 1997;12:14-25.

35 Roberts WG, Hasan T. Role of neovasculature and vascular permeability on the tumor retention of photodynamic agents. Cancer Res 1992;52:924-30.

36 Zhou C. Mechanisms of tumor necrosis induced by photodynamic therapy. F Photochem Photobiol B 1989;3:299-318.

37 Husain D, Miller JW, Michaud N, et al. Intravenous infusion of liposomal benzoporphyrin derivative for photodynamic therapy of experimental
choroidal neovascularization. Arch Ophthalmol 1996;114:978-85.

38 Schmidt-Erfurth U, Birngruber R, Hasan T. Photodynamic therapy in ocular vascular disease, Laser Physics 1998;8:191-8.

39 Aveline B, Hasan T, Redmond RW. Photophysical and photosensitizing properties of benzoporphyrin deriva

40 Allison BA, Pritchard PH, Levy JG. Evidence for low-density lipoprotein receptor-mediated uptake of benzoporphyrin derivative. Br f Cancer 1994; 69:833-9.

41 Husain D, Kramer M, Michaud N, et al. Photodynamic therapy (PDT) of experimental choroidal neovascularization (CNV) using benzoporphyrin
derivative (BPD-MA): dye delivery and treatment parameters. Invest Ophthalmol Vis Sci 1995;36:S225.

42 Gaffney J, West D, Arnold F, et al. Differences in the uptake of modified low density lipoproteins by tissue cultured endothelial cells. F Cell Sci 1985;79: $317-25$.

43 Fogelman AM, Berliner JA, Van Lenten BJ, et al. Lipoprotein receptors and endothelial cells. Sem Thromb Hemost 1988;14:206-9.

44 Kramer M, Kenney AG, Delori F, et al. Imaging of experimental choroidal neovascularization (CNV) using liposomal benzoporphyrin derivative mono-acid (BPD-MA) angiography. Invest Ophthalmol Vis Sci 1995;36: S236.

45 Schmidt-Erfurth U, Bauman W, Gragoudas E, et al. Photodynamic therapy of experimental choroidal melanoma using lipoprotein-delivered benzoporphyrin. Ophthalmology 1994;101:89-99.

46 Schmidt-Erfurth U, Hasan T, Schomacker K, et al. In vivo uptake of liposomal benzoporphyrin derivative and photothrombosis in experimenta corneal neovascularization. Lasers Surg Med 1995;17:178-88.

47 Haimovici R, Kramer M, Miller JW, et al. Localization of lipoproteindelivered benzoporphyrin derivative in the rabbit eye. Curr Eye Res 1997;16:83-90.

48 Kramer M, Miller JW, Michaud N, et al. Liposomal benzoporphyrin derivative verteporfin in photodynamic therapy. Selective treatment of choroidal neovascularization in monkeys. Ophthalmology 1996;103:427-38.

49 Schmidt-Erfurth U, Hasan T, Flotte T, et al. Photodynamic therapy of experimental intraocular melanoma using benzoporphyrin lipoprotein. Ophthalmologe 1994;91:348-56.

50 Richter AM, Waterfield E, Jain AK, et al. Photosensitising potency of structural analogues of benzoporphyrin derivative (BPD) in a mouse tumour tural analogues of benzoporphyrin

51 Miller JW, Walsh AW, Kramer M, et al. Photodynamic therapy of experimental choroidal neovascularization using lipoprotein-delivered benzoporphyrin. Arch Ophthalmol 1995;113:810-18.

52 Husain D, Kramer M, Kenny AG, et al. Effects of photodynamic therapy using verteporfin on experimental choroidal neovascularization and normal retina and choroid up to 7 weeks after treatment. Invest Ophthalmol Vis Sci 1999;40:2322-31

53 Reinke $\mathrm{MH}$, Canakis C, Husain D, et al. Verteporfin photodynamic therapy retreatment of normal retina and choroid in the cynomolgus monkey. Ophthalmology 1999;106:1915-23.

54 Miller JW, Schmidt-Erfurth U, Sickenberg M, et al. Photodynamic therapy with verteporfin for choroidal neovascularization caused by age-related macular degeneration. Results of a single treatment in a phase 1 and 2 macular degeneration. Results of a single
study. Arch Ophthalmol 1999;117:1161-73.

55 Schmidt-Erfurth U, Miller JW, Sickenberg M, et al. Photodynamic therapy with verteporfin for choroidal neovascularization caused by age-related macular degeneration. Results of retreatments in a phase 1 and 2 study. Arch Ophthalmol 1999;117:1177-87.

56 Sickenberg M, Schmidt-Erfurth U, Miller JW, et al. A preliminary study of photodynamic therapy using verteporfin for choroidal neovascularization in pathologic myopia, ocular histoplasmosis syndrome, angoid streaks, and diopathic causes. Arch Ophthalmol 2000;118:327-36.

57 Guyer DR, Yannuzzi LA, Ladas I, et al. Indocyanine green-guided laser photocoagulation of focal spots at the edge of plaques of choroidal neovascularization. Arch Ophthalmol 1996;114:693-7.

$58 \mathrm{Lim}$ JI, Aaberg TM, Capone A Jr, et al. Indocyanine green angiographyguided photocoagulation of choroidal neovascularization associated with
retinal pigment epithelial detachment. Am f Ophthalmol 1997;123:524-32.

59 Bressler NM, Silva JC, Bressler SB, et al. Clinicopathologic correlation of drusen and retinal pigment epithelial abnormalities in age-related macular drusen and retinal pigment epithelial abn

60 Reichel E, Duker IS, Guyer DR. Indocyanine green dye-enhanced diode laser photocoagulation of poorly defined subfoveal choroidal neovascularisation. Ophthalmic Surg 1994;25:195-201.

61 Staurenghi G, Orzalesi N, La Capria A, et al. Laser treatment of feeder vessels in subfoveal choroidal neovascular membranes. A revisitation using dynamic indocyanine green angiography. Ophthalmology 1998;105:2297305.

62 Shiraga F, Ojima Y, Matsuo T, et al. Feeder vessel photocoagulation of subfoveal choroidal neovascularization secondary to age-related macular degeneration. Ophthalmology 1998;105:662-9.

63 Roider J, Michaud NA, Flotte TJ, et al. Response of the retinal pigment epithelium to selective photocoagulation. Arch Ophthalmol 1992;110:1786-92.

64 Roider J, Brinkmann R, Wirbelauer C, et al. Subthreshold (retinal pigment epithelium) photocoagulation in macular diseases: a pilot study. $\mathrm{Br} \mathcal{f} \mathrm{Oph}$ thalmol 2000;84:40-7.

65 Shields CL, Shields JA, Cater J, et al. Transpupillary thermotherapy for choroidal melanoma. Tumor control and visual results in 100 consecutive cases. Ophthalmology 1998;105:581-90.
66 Reichel E, Berrocal AM, Ip M, et al. Transpupillary thermotherapy of occult subfoveal choroidal neovascularization in patients with age-related macular degeneration. Ophthalmology 1999;106:1908-14.

67 Bressler NM. Submacular surgery. Are randomized trials necessary? Arch Ophthalmol 1995;113:1557-60.

68 Olsen TW. Submacular surgery for age-related macular degeneration. Sem Ophthalmol 1997;12:34-44

69 Thomas MA, Grand MG, Williams DF, et al. Surgical management of subfoveal choroidal neovascularization. Ophthalmology 1992;99:952-68.

70 Gass JDM. Biomicroscopic and histopathologic considerations regarding the feasibility of surgical excision of subfoveal neovascular membranes. $\mathrm{Am}$ f Ophthalmol 1994;118:285-98.

71 Grossniklaus HE, Gass JDM. Clinicopathologic correlations of surgically excised type 1 and type 2 submacular choroidal neovascular membranes. Am $\mathcal{F}$ Ophthalmol 1998;126:59-69.

72 Merrill PT, LoRusso FJ, Lomeo MD, et al. Surgical removal of subfoveal choroidal neovascularization in age-related macular degeneration. Ophthalmology 1999;106:782-9.

73 Lewis H. Subfoveal choroidal neovascularization: is there a role for submacular surgery? Am f Ophthalmol 1998;126:127-9.

74 Lewis H, VanderBrug Medendorp S. Tissue plasminogen activator-assisted surgical excision of subfoveal choroidal neovascularization in age-related macular degeneration. A randomized double-masked trial. Ophthalmology 1997;104:1847-52.

75 Thomas MA, Dickinson JD, Melberg NS, et al. Visual results after surgical removal of subfoveal choroidal neovascular membranes. Ophthalmology 1994;101:1384-96.

76 Machemer R, Steinhorst UH. Retinal separation, retinotomy, and macular relocation: II. A surgical approach for age-related macular degeneration? Graefes Arch Clin Exp Ophthalmol 1993;231:635-41.

77 Wolf S, Lappas A, Weinberger AWA, et al. Macular translocation for surgical management of subfoveal choroidal neovascularizations in patients with AMD: first results. Graefes Arch Clin Exp Ophthalmol 1999;237:51-7.

78 Eckardt C, Eckardt U, Conrad H-G. Macular rotation with and without counter-rotation of the globe in patients with age-related macular degeneration. Graefes Arch Clin Exp Ophthalmol 1999;237:313-25.

79 de Juan E, Jr., Loewenstein A, Bressler NM, et al. Translocation of the retina for management of subfoveal choroidal neovascularization II: a preliminary report in humans. Am f Ophthalmol 1998;125:635-46.

80 Kychenthal A, Stanga PE, Fitzke FW, et al. Retinal pigment epithelium translocation after choroidal neovascular membrane removal in age-related macular degeneration. Invest Ophthalmol Vis Sci 1999;40:S207.

81 Enzmann V, Faude F, Wiedemann P, et al. Immunological problems of transplantation into the subretinal space. Acta Anat (Basel) 1998;162:178-83.

82 Gouras P, Flood MT, Kjeldbye H. Transplantation of cultured human retinal cells to monkey retina. An Acad Bras Cienc 1984;56:431-43.

83 del Cerro M, Lazar ES, Diloreto D Jr. The first decade of continuous progress in retinal transplantation. Microsc Res Tech 1997;36:130-41.

84 Kohen L, Faude F, Enzmann V, et al. Heterologous iris pigment epithelium transplantation in a rabbit model. Invest Ophthalmol Vis Sci 1998;39:S97.

85 Das T, del Cerro M, Jalali S, et al. The transplantation of human fetal neuroretinal cells in advanced retinitis pigmentosa patients: results of a long-term safety study. Exp Neurol 1999;157:58-68.

86 Mohand-Said S, Deudon-Combe A, Hicks D, et al. Normal retina releases a diffusible factor stimulating cone survival in the retinal degeneration mouse. Proc Natl Acad Sci USA 1998;95:8357-62.

87 Chow AY, Chow VY. Subretinal electrical stimulation of the rabbit retina. Neurosci Lett 1997;225:13-16.

88 Peyman G, Chow AY, Liang C, et al. Subretinal semiconductor microphotodiode array. Ophthalmic Surg Lasers 1998;29:234-41.

89 Zrenner E, Miliczek K-D, Gabel VP, et al. The development of subretinal microphotodiodes for replacement of degenerated photoreceptors. $O p h$ thalmic Res 1997;29:269-80.

90 Humayun MS, de Juan EJ, Weiland JD, et al. Pattern electrical stimulation of the human retina. Vis Res 1999;39:2569-76.

91 Humayun MS, de Juan E, Jr., Dagnelie G, et al. Visual perception elicited by electrical stimulation of retina in blind humans. Arch Ophthalmol 1996;114: 40-6.

92 Sherr DL, Finger PT. Radiation therapy for age-related macular degenera97;12:26-33.

93 Gragoudas ES 1996 Jules Gonin lecture of the Retina Research Foundation. Long-term results after proton irradiation of uveal melanomas. Graefes Arch Clin Exp Ophthalmol 1997;235:265-7.

94 Chakravarthy U, Houston RF, Archer DB. Treatment of age-related subfoveal neovascular membranes by teletherapy: a pilot study. $\mathrm{Br} F$ Ophthalmol 1993;77:265-73.

95 Stalmans P, Leys A, Van Limbergen E. External beam radiotherapy (20 Gy, 2 Gy fractions) fails to control the growth of choroidal neovascularization in age-related macular degeneration: a review of 111 cases. Retina 1997;17:481-92.

96 Spaide RF, Guyer DR, McCormick B, et al. External beam radiation therapy for choroidal neovascularization. Ophthalmology 1998;105:24-30.

97 Tholen AM, Meister A, Bernasconi PP, et al. Radiotherapy for choroidal neovascularization in age-related macular degeneration. A pilot study using lowversus high-dose photon beam radiation. Ophthalmologe 1998;95:691-8.

98 Soubrane G. Affections acquises de l'epithelium pigmentaire rétimen. Marseille: Fuery-Lamy, 1995:169-204.

99 Donati G, Soubrane D, Quaranta M, et al. Radiotherapy for isolated occult subfoveal neovascularisation in age related macular degeneration: a pilot study. Br f Ophthalmol 1999;83:646-51.

$100 \mathrm{Holz}$ FG, Engenhart-Cabillic R, Unnebrink K, et al. A prospective, randomized, double-blind trial on radiation therapy for neovascular age-related macular degeneration (RAD Study). Ophthalmology 1999;106:2239-47.

101 Bergink G-J, Hoyng CB, van der Maazen RWM, et al. A randomized controlled clinical trial on the efficacy of radiation therapy in the control of subfoveal choroidal neovascularization in age-related macular degeneration: radiation versus observation. Graefes Arch Clin Exp Ophthalmol 1998;236:321-5.

102 Pharmacological Therapy for Macular Degeneration Study Group. Interferon alfa-2a is ineffective for patients with choroidal neovascularization secondary to age-related macular degeneration. Results of a prospective randomized placebo-controlled clinical trial. Arch Ophthalmol 1997;115:865-72.

103 D'Amato RJ, Loughnan MS, Flynn E, et al. Thalidomide is an inhibitor of angiogenesis. Proc Natl Acad Sci USA 1994;91:4082-5. 
104 Bullard LE, Rajaratnam VS, Collier RJ, et al. Evidence that AL-3789 inhibits retinal neovascularization in an animal model of ROP by inducing inhibits retinal neovascularization in an animal model of

105 Garcia CR, Rivero ME, Hagedorn M, et al. Efficacy of AG3340, a selective inhibitor of matrix metalloproteases in an animal model of retinal neovascularization. Invest Ophthalmol Vis Sci 1999;40:S617.

106 Krott R, Kociok E, Stappler E, et al. The apoptosis protein p53 could be detected in human microvascular endothelial cells treated by genistein. Invest Ophthalmol Vis Sci 1999;40:S618.

107 Penn JS, Roberto KA, Bullard LE. Inhibition of retinal neovascularization by a broad spectrum matrix metalloproteinase inhibitor in an animal model of ROP. Invest Ophthalmol Vis Sci 1999;40:S618.

108 Kenyon BM, Browne F, D'Amato RJ. Effects of thalidomide and related metabolites in a mouse corneal model of neovascularization. Exp Eye Res 1997;64:971-8.

109 Snyder RK, Runge PE. Thalidomide and neovascular age-related macular degeneration (NVARMD). Invest Ophthalmol Vis Sci 1998;39:S385.

110 Frank RN. Growth factors in age-related macular degeneration: pathogenic and therapeutic implications. Ophthalmic Res 1997;29:341-53.

111 Aiello LP. Vascular endothelial growth factor and the eye: biochemical mechanisms of action and implications for novel therapies. Ophthalmic Res 1997;29:354-62.

112 Kvanta A, Algvere PV, Berglin L, et al. Subfoveal fibrovascular membranes in age-related macular degeneration express vascular endothelial growth factor. Invest Ophthalmol Vis Sci 1996;37:1929-34.

113 Wada M, Ogata N, Otsuji T, et al. Expression of vascular endothelial growth factor and its receptor (KDR/flk-1) mRNA in experimental choroidal neovascularization. Curr Eye Res 1999;18:203-13.

114 Verteporfin In Photodynamic Therapy (VIP) Study Group. Photodynamic therapy of subfoveal choroidal neovascularization in pathologic myopia with verteporfin: one-year results of a randomized clinical trial-VIP Report No 1. Ophthalmology (in press).
115 Kostenich G, Orenstein A, Roitman L, et al. In vivo photodynamic therapy with the new near-IR absorbing water soluble photosensitizer lutetium texaphyrin and a high intensity pulsed light delivery system. I Photochem Photobiol B 1997;39:36-42.

116 Graham KB, Arbour JD, Connolly EJ, et al. Digital angiography using lutetium texaphyrin in a monkey model of choroidal neovascularization. Invest Ophthalmol Vis Sci 1999;40:S402.

117 Primbs GB, Casey R, Lin GC, et al. Photodynamic therapy of corneal neovascularization using tin ethyl etiopurpurin (SnET2). Invest Ophthalmol Vis Sci 1997;38:S702.

118 Thomas EL, Rosen R, Murphy R, et al. Purlytin (SnET2)-photodynamic therapy produces closure of subfoveal choroidal neovascularization in humans. Invest Ophthalmol Vis Sci 1998;39:S242.

119 Thomas EL, Rosen R, Murphy R, et al. Visual acuity stabilizes after a single treatment with SnET2 photodynamic therapy in patients with subfoveal choroidal neovascularization. Invest Ophthalmol Vis Sci 1999;40:S401.

120 Moshfeghi DM, Peyman GA, Kazi AA, et al. Mono-L-aspartyl chlorin e6 (NPe6) angiography of the retina in pigmented rats, rabbits, and monkeys. Invest Ophthalmol Vis Sci 1999;40:S322.

121 Wong Kee Song L-M, Wang KK, Zinsmeister AR. Mono-L-aspartyl chlorin e6 (Npe6) and hematoporphyrin derivative $(\mathrm{HpD})$ in photodynamic therapy administered to a human cholangiocarcinoma model. Cancer 1998;82:421-7.

122 The Age-Related Eye Disease Study Research Group. The Age-Related Eye Disease Study (AREDS): design implications. AREDS report no 1. Control Clin Trials 1999;20:573-600.

123 The Age-Related Eye Disease Study Research Group. The Age-Related Eye Disease Study (AREDS): a clinical trial of zinc and antioxidants. AREDS study report no. 2. F Nutr 2000;130:1516S-19S.

124 Ho AC. Laser treatment in eyes with drusen. Curr Opin Ophthalmol 1999; 10:204-8

\section{Cover illustration: Birds of a feather}

The barking owl (Ninox connivens) is a medium to large Australian owl with bright yellow eyes and interesting vocalisations. This hawk-like owl is agile and aggressive and could be described as crepuscular. Others would describe these birds as semidiurnal as they have been seen taking live prey in broad daylight.

One of the bird's vocalisations provides a reason for its name because it does indeed sound like a barking dog (a gruff double bark), and it was not understood as the call of an owl until the 1930s. The bird was known as the winking owl before that time. Both sexes make the same call, but the female's call is higher pitched and seems to penetrate the dense foliage of the forest better than the male's. The other principal call, referred to as the "screaming woman", mystified ornithologists for decades until satisfactorily identified as also belonging to the barking owl. The "screaming woman" call is only heard occasionally, generally in the Australian autumn months of March and April and is given 8-10 times over approximately 90 seconds. Indeed, the sound resembles the cry a woman might utter in abject terror. This call is usually given outside of the breeding season, but its significance is unknown.

These robust birds are versatile predators and take a great variety of prey including insects, fish, mammals, marsupials, and many bird species, including ducks and even tawny frogmouths. Their ideal habitat is open country with large trees for roosting, but the owl's range extends even into the rain forest. Both sexes are fearless and pugnacious at the nest. The upper part of the cover shows the face of a barking owl. The bottom half of the cover deserves a bit more explanation.

Birds are covered in feathers. Feathers are composed of keratin and are among the strongest material per weight produced by an animal. There are at least four different types of feathers including contour and flight feathers, down, filoplumes, and powder-down feathers.
Look closely around the eyes of the barking owl and you will see what look like eyelashes. These are filoplumes, modified feathers that resemble hair in both appearance and function. Filoplumes come in at least two varieties, both of which can be found around the eyes. The bristles (subclass of filoplumes) are stiff, straight, and most closely resemble lashes. Most filoplumes have a sensory function, acting as movement detectors.

The bottom half of the cover exhibits two different electron micrographs to illustrate the similarity between filoplumes and lashes. The left hand electron micrograph is a shaft of a human lash $(\times 3673)$ and the right hand one is of a shaft of a periocular avian filoplume simulating a lash $(\times 3673)$. If you were not familiar with electron microscopy of eyelashes, you might guess that the photographs were reversed in the printing process. We assure you they are not reversed.

Convergent evolution has created the same form for the periocular protection of the ocular surface with lashes or lash-like structures to prevent stray matter from entering the eye from above and pressure and movement detection to provide avoidance when necessary (the blink reflex). The avian outer eyelids are very different from human eyelids as they utilise smooth muscle and rarely close during waking hours. None the less, the lash-like filoplumes have evolved in a manner very similar to that of human hair. Or, perhaps human hair has evolved to look like filoplumes, since birds are evolutionarily older than humans. In either case, it would appear that ocular protection with stiff sensitive structures is a preferred adaptation.-Ivan $R$ Schwab, MD, UC Davis Department of Ophthalmology, $4860 Y$ Street, Suite 2400, Sacramento, CA 95817, USA (irschwab@ucdavis.edu).

Electron microscopy provided by Robert Munn, MD

Thanks to the Perth Zoo for allowing the photography and to Paul McMenamin, $\mathrm{PhD}$, for enabling the photography. 